\title{
On the Road to "Pre-K for All": The Launch of UPK in New York City
}

\section{Citation}

Crawford, Susan P., Mary-Catherine Lader, and Maria Smith. 2015. "On the Road to'Pre-K for All': The Launch of UPK in New York City." Berkman Klein Center for Internet and Society Research Publication 2015-9.

\section{Published Version}

https://cyber.harvard.edu/publications/2015/UPK_in_NYC

\section{Permanent link}

http://nrs.harvard.edu/urn-3:HUL.InstRepos:28552585

\section{Terms of Use}

This article was downloaded from Harvard University's DASH repository, and is made available under the terms and conditions applicable to Other Posted Material, as set forth at http:// nrs.harvard.edu/urn-3:HUL.InstRepos:dash.current.terms-of-use\#LAA

\section{Share Your Story}

The Harvard community has made this article openly available.

Please share how this access benefits you. Submit a story.

\section{Accessibility}


Research Publication No. 2015-9

May 24, 2015

On the Road to "Pre-K for All":

The Launch of UPK in New York City

\author{
Susan Crawford \\ Mary-Catherine Lader \\ Maria Smith
}

This paper can be downloaded without charge at:

The Berkman Center for Internet \& Society Research Publication Series: https://cyber.law.harvard.edu/publications/2015/UPK_in_NYC

The Social Science Research Network Electronic Paper Collection: Available at SSRN: http://ssrn.com/abstract=2610694 


\section{On the Road to "Pre-K for All": The Launch of UPK in New York City}

By Susan Crawford, Mary-Catherine Lader, and Maria Smith

May 24, 2015

Berkman Center for Internet \& Society Co-Director Susan Crawford, Harvard Law School student Mary-Catherine Lader, and Harvard College student Maria Smith prepared this case study. 


\section{Executive Summary}

Over the spring and summer of 2014, New York City put in place a full-day universal prekindergarten (UPK) program. The blistering pace, enormous scale, and administrative complexity of this rollout were all striking: a program that did not exist when funding for it was finalized in March 2014 had put 53,250 four-year-olds in more than 1700 new full-day programs by the first day of school in September. This report provides a detailed account of the launch. It includes an extensive discussion of the city's use of data science techniques; the city was able to combine and analyze databases in such a way that outreach teams could contact households that were likely to include four-year-olds and help interest parents sign up, all with a sharp eye for the privacy of New Yorkers. The launch as a whole combined the energy of a micro-targeted political campaign with service-oriented, street-level energy, and the lessons New York City learned in the course of this work should be useful to other cities and states.

\section{Key Findings}

- Leadership is central. Given the administrative thickets that had to be hacked through in order for UPK to get off the ground in New York City on a large scale, the launch would likely have failed absent Mayor de Blasio's frequent involvement.

- Data systems may not be ready, but that is not a reason not to launch. New York City decided that the key interface it needed was the campaign-management function used by its outreach teams. Other data systems-for permitting, teacher recruitment, applications, and enrollment, among other elements of the rollout-were revised as needed, an approach that allowed the city to make agile, problem-solving decisions on the fly. Had the city waited until it had a perfect, bells-and-whistles system in place it likely would have missed the first day of school and might have ended up with a system ill-suited to its needs.

- Having adequate in-house coding and data analytics resources is essential. New York is a leader in this area, but even in New York City data science may be insufficiently standardized, respected, and persistent in individual departments. Government needs more people who can write code and work with data as well as manipulate Excel spreadsheets, at all levels.

- Mixing data science with grassroots campaign/organizing techniques and a commitment to affirmative government assistance can be a winning combination. Merely making UPK services widely available would not have worked in 2014. The de Blasio administration had to find the right households in an organized way and then help both parents and new program sites travel the bureaucratic path towards the first day of school. Hands-on, individualized assistance made the difference. 


\section{Table of Contents}

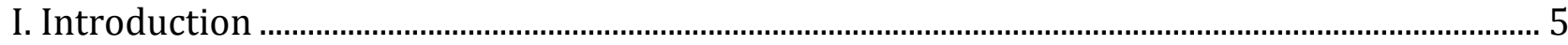

II. Timeline

A. Recruitment

B. Site Approval and Permitting............................................................................................................. 13

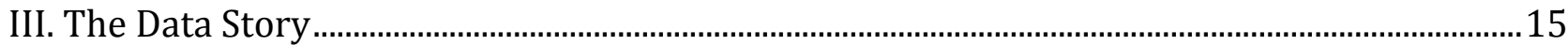

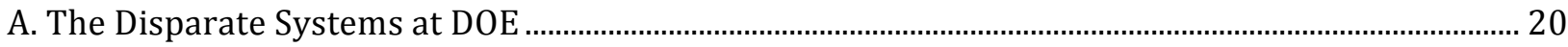

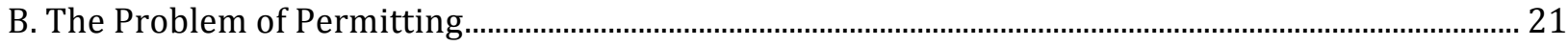

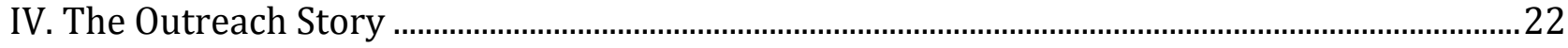

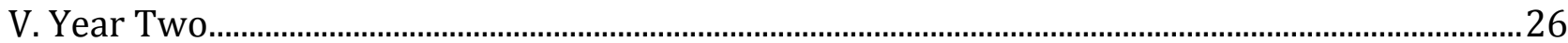

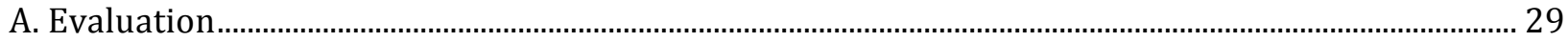

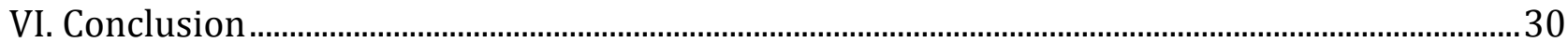




\section{Introduction}

The theoretical case for ensuring that all American children have access to quality early childhood education is strong. ${ }^{1}$ Well-designed programs can generate high returns for both individuals and society by avoiding — in the long run — costs that might otherwise be caused by delinquency, crime, and inability to access the labor market. Indeed, the benefits to society of pre-kindergarten may go beyond dollars: flourishing, productive lives require skills like openness, engagement with other people, the ability to plan, self-control, and resilience, and according to a raft of academic studies many of those skills can be enhanced by very-earlychildhood quality education programs. Additionally, the alarming "vocabulary gap" between rich and low-income children, amounting to as many as eleven million words in the first five years of a child's life, may be lessened through quality preschool experiences. ${ }^{2}$

Notwithstanding this evidence, fewer than three in ten four-year-olds nationwide are enrolled in a high-quality preschool program. ${ }^{3}$ America is toward the bottom of the list of developed countries when it comes to percentages of four-year-olds in preschool. ${ }^{4}$ This standing is likely correlated with the country's growing inequality-which in turn poses a substantial risk to the nation's future economic health. ${ }^{5}$

Calls for reform will gain in strength: More than two-thirds of Americans favor using federal funding to expand access to quality pre-kindergarten programs, and the need for universal pre-kindergarten is likely to be one of the domestic policy themes of the 2016 presidential campaign. ${ }^{6}$ But the major reform movement needed to move pre-K from theory to practice on a national scale will require a level of investment that Congress is unlikely to approve at this moment in history, particularly in the absence of working demonstration models to which legislators can point.

As a result, states and cities are the government actors stepping up to implement universal pre-kindergarten programs. (By "universal," Americans mean that any family in a given geographic area can send four year-olds to a school program at no cost.) The implementation and project management challenges of initiating these programs are substantial, and the hope is that lessons learned by local programs can be replicated successfully across the country. Someday, the reasoning runs, universal pre-K will become inevitable and expected across the country.

Over the spring and summer of 2014, New York City put in place its own full-day universal pre-kindergarten (UPK) program. The blistering pace, enormous scale, and administrative

\footnotetext{
${ }^{1}$ Steven Bernett, "Expanding Access to Quality Pre-K is Sound Public Policy," National Institute for Early Childhood Research at Rutgers, December 2013.

2 John Merrow, "The PreSchool Education Issues in America," HufFINGTON Post (April 6, 2011)

http://www.huffingtonpost.com/john-merrow/preschool-education-america_b_845501.html.

${ }^{3}$ National Center for Education Statistics, Early Childhood Longitudinal Study, Birth Cohort, Longitudinal 9-monthKindergarten Restricted-Use Data File, Washington, DC, December 2010.

${ }^{4}$ OECD, "Education at a Glance: OECD Indicators 2012," September 2012.

${ }^{5}$ Lawrence H. Summers and Ed Balls, "Report of the Commission on Inclusive Prosperity," the Center For American Progress, January 2015.

${ }^{6}$ Jeffrey M. Jones, “In U.S., 70\% Favor Federal Funds to Expand Pre-K Education,” GALluP (September 8, 2014) http://www.gallup.com/poll/175646/favor-federal-funds-expand-pre-education.aspx.
} 
complexity of this rollout were all striking: a program that did not exist when funding for it was finalized in March 2014 had put 53,250 four-year-olds in more than 1700 new full-day programs by the first day of school in September.

In order for this to happen, tens of thousands of parents in New York City had to learn about UPK for the first time. Spreading that awareness across an enormous city was difficult enough; effectively targeting the parents of four-year-olds - when cohorts of four-year-olds had not been a focus in the past-posed additional challenges. Then those parents had to apply for and be matched to a program. Somehow, the seats available in those programs had to match demand, both in terms of numbers and location. The classrooms and other facilities used for those programs had to be permitted and checked for safety by multiple city departments. New teachers had to be hired and trained. More than two dozen city agencies had to cooperate in innumerable ways over a very short timescale. Along the way, data systems had to be invented or repurposed that could handle this new city program and allow UPK to be sustained and evaluated into the future. These implementation and project management challenges posed extraordinary hurdles to the rollout of UPK on the scale attempted in New York City in 2014. Many people thought it couldn't be done.

The story of New York City's UPK rollout is an all-hands-on-deck narrative. Without Mayor Bill de Blasio's strong leadership and persistent focus a successful largescale launch of UPK would have been impossible. The clarity of the mayor's big, difficult, urgent goal-Pre-K For All in two years-forced accelerated attention to the program across the city that spurred activity and, in itself, increased capacity in the city to get the job done. Deputy Mayor Rich Buery drove the bonecrushingly difficult cross-agency work that was essential. Deputy Chancellor of Strategy and Policy Josh Wallack made the operation work. Good ideas live and die by project management in government, and heroic efforts along these lines-backed by the unstinting support of the mayor-made UPK a reality in New York City. Hundreds of New York City public servants took up the problem of getting UPK off the ground with conviction and energy. Sophisticated campaign management had outreach workers and volunteers visiting laundromats, nail salons, and parades-speaking in person at more than 500 events and talking directly to more than 520,000 New Yorkers.

It is also a technology story. As Sophia Pappas, Chief Executive Officer of the Division of Early Childhood Education, NYC Department of Education, puts it, the thing that surprised her, the thing she wished she had known before the 2014 implementation push, was "the importance of comprehensive data systems that could support a complex rollout." The city was able to get the launch off the ground by carefully combining cleaned and disparate data sources in such a way that outreach teams could effectively reach the parents of four-yearolds-combining the energy of a micro-targeted political campaign with a crucial government service, all with a sharp eye on the potential privacy concerns of New Yorkers.

Other tech parts of the story are continuing to evolve. The city quickly repurposed existing systems and created new ones ("we were able to make it work," says Pappas), but the data systems in place at the outset of the effort hadn't been designed with UPK in mind and weren't immediately capable of generating the up-to-date, comprehensive information the city needed to manage the rollout. Deputy Mayor Buery is blunter: he says the data systems in place at the outset were a "disaster." The city made it work by making systems designed for 
one purpose serve another, by getting systems to talk to one another that hadn't done so in the past, and by continually checking and updating data systems using manual processes. A great deal of shoe leather and astonishing goodwill was involved in making it work.

A major strength displayed by the city was the agility with which it dealt head-on with the technology systems needed to make the UPK rollout a success: the city never let the perfect be the enemy of the good, worked with what it had as much as possible (rather than stopping dead to create entire new systems from scratch), and continued to revise its approach on the fly as needed. Mindful that data systems could make or break the rollout—and recalling the injury done to the overall healthcare narrative by initial problems with Healthcare.gov in October 2013 - the city made sure everyone involved understood the centrality of technology to the launch effort.

Finally, the UPK rollout story sheds light on the possibility of changing citizens' perception of government. City public employees used a variety of campaign outreach techniques targeted by data and managed with the help of an online platform to reach parents of four-year-olds, but they didn't stop there. They stayed by the side of parents to help them through the enrollment process, following up with 1.2 million phone calls, emails, and texts. In many cases, they dealt with the clunky enrollment system the city used so that parents and schools wouldn't have to. And public employees worked extraordinarily closely with community early childhood centers (called CBECCs in 2013-14, for Community-Based Early Childhood Centers, now called Early Education Centers, which is the term used throughout this case study) to make sure they were ready for students at the start of the school year. All of this made citizens feel as if their local government was helping them. As Deputy Mayor Rich Buery puts it, "So many times, particularly for low-income families, your experience with the government is one of fear and negative authority. And this was a pure positive experience with government. People really felt that."

As of April 2015, when this case study was drafted, city officials in New York were cautiously optimistic about the success of Year One. Even though formal evaluation results were not yet available, UPK attendance, a strong indicator of parental happiness with the program, had been high over the fall term: $90 \%$ at both "district" (public) and Early Education Centers UPK programs. "We worried about whether children would actually come, whether parents would take it seriously," Deputy Mayor Buery says, and it appears that parents did take the program seriously. He acknowledges there are outliers, largely Early Education Centers, experiencing lower participation.

The city is now planning to facilitate a much larger program for September 2015, with 73,000 four-year-olds in seats-representing substantial progress towards the mayoral goal 
of "Pre-K For All."7 A common application for district and Early Education Center programs is now functioning, meaning both that the interface between those programs and parents has been standardized and that these two formerly separate education categories are now treated similarly by the back-office systems operated by the city. The data systems are working better (and playing better with one another), making management, visualization, and evaluation far easier.

Not that everything is perfect. The city's UPK implementation is "a bell curve," according to Matthew Klein, Executive Director of the Center for Economic Opportunity, and the Senior Advisor for Service Innovation in the Mayor's Office of Operations. He continues: "We have to be in continuous improvement mode. We want to uncover the things that are not great so we can work on them." Agile development continues. Indeed, Year Two will pose significant challenges: the network of pre-existing Early Education Centers has likely been thoroughly tapped, making it necessary for the city to push for the opening of additional, new centers in city neighborhoods where demand is high and civic/commercial fabric may be weak. Additionally, new, affordable spaces in the many high-rent areas of the city will be difficult to find. The city needs to hire a large number of new teachers for Year Two; ensuring that the professional development of the teachers involved is aimed at ensuring a quality education for every pre-K child presents an enormous challenge all by itself.

As the push for Year Two began, city employees were proud of what they had done so far. Sophia Pappas says the NYC UPK rollout shows that "doing big transformative things on a fast timeline is possible" in government. She continues: "It's not to say that you shouldn't be thoughtful and mindful of challenges, but with the right people, the right leadership, and just a relentless commitment to results and constant problem-solving, you can do it." Jasmine Fernandez, a leading neighborhood enrollment specialist in Brooklyn for Year One and Partnership Outreach Manager for Year Two, says that when Mayor de Blasio announced on August 28, 2014 that the city had met its enrollment targets she was "so overjoyed." She continues: "I was extremely proud. Just really proud and humbled to be in the room saying, 'Wow, we did it.'"

Given the importance of local demonstrations of what works in implementing quality UPK programs, the narrative of this rollout should not be an "only in New York" story. As Deputy Mayor Buery puts it, "We need to start to communicate to different people around the country that this was money well spent."

To be sure, New York had several advantages on its side: a large network of existing halfday Pre-K programs at Early Education Centers that could be converted to full-day programs, major local universities that were willing and able to help with teacher professional

\footnotetext{
7 "For all" may be a moving target. In 2014, the city calculated that 73,250 children would need free, high-quality, full-day pre-K by the 2015-16 school year. ["Ready to Launch: New York City's Implementation Plan for Free, High-Quality, FullDay Universal Pre-Kindergarten," Office of the Mayor, New York City, January 2014.] This estimate was based on the number of children enrolled in district and charter school kindergarten at the time $(81,748)$, minus the estimated number of children who would require full-day pre-K in a non-public setting $(8,498)$. The target for the $2014-15$ school year was 53,604 , with the full 73,000 to be reached the following year. These numbers do not include children enrolled in private kindergartens. As UPK becomes integrated into the educational system, parents who might otherwise sent their children to private institutions may migrate to UPK programs, making the denominator for "all" a larger number.
} 
development and certification, access to every form of media for outreach, heroic in-house talent in both project management and data science, substantial funding made available by the state, and a platoon of neighborhood volunteers. Not all cities have these resources.

But what New York City has learned in the course of implementing UPK is that committed leadership plus thoughtfully-deployed data can be used to improve citizens' perception of government and change lives in a relatively short time. As Pappas puts it, "We have learned a lot about how to connect to people in a very service-oriented manner. It's a different way of thinking about government." This lesson is worth learning by cities of any size.

This case study provides a timeline of the 2014 NYC UPK rollout. It also describes in detail the outreach efforts made by New York City and the data science work that made that outreach effective. It then sketches the system challenges the city faced in deploying this program and describes the City's initial plans for adding more than 18,000 seats in Year Two-the 2015-16 school year.

\section{Timeline}

Although the 2014 implementation of New York City's UPK program happened at a scorching pace, the city was not starting from scratch. Mayor Bill de Blasio had been committed to the idea of UPK since at least as early as October 4, 2012, when, as Public Advocate de Blasio, he appeared before the Association for a Better New York to make a speech about economic development. De Blasio and his team decided to avoid the usual talking points about job creation and instead focus on education. According to Jeff Merritt, now the Director of Innovation for the Mayor's Office of Technology and Innovation, who was on de Blasio's staff at the time of the ABNY speech, "“He was speaking to a group of the wealthiest New Yorkers and saying, 'We can't build the economy of the future without leveling the playing field from day one for all of our kids."'

Then, in the 2013 mayoral election, UPK became one of two campaign promises candidate de Blasio promised would be implemented in his first 100 days in office. (The other was ending the police department's "stop-and-frisk" practices.) Once elected, de Blasio would need money to get this done-about $\$ 340$ million-and an operation in place to make sure it happened.

The money issue prompted a well-publicized tussle between new Mayor de Blasio and New York State Governor Andrew Cuomo. The mayor wanted to tax high earners in New York City to fund the program; the governor, who was facing re-election, had promised to keep taxes low and thought the state should be in charge. Governor Cuomo pointed out that if funding for UPK depended on taxing wealthy citizens in particular cities smaller and poorer cities in the state would be at a disadvantage. ${ }^{8}$

\footnotetext{
${ }^{8}$ Michael M. Grynbaum and Thomas Kaplan, "Pre-K Plan Puts Cuomo at Odds with de Blasio on Funding," THE NEW YoRK TIMES (January 21, 2014) http://www.nytimes.com/2014/01/22/nyregion/cuomo-prekindergarten-proposal.html.
} 
In the end, both de Blasio and Cuomo claimed victory on March 29, 2014 when Cuomo's state budget included $\$ 300$ million to fund UPK in New York City. Mayor de Blasio received a five-year, $\$ 1.5$ billion commitment from the state.

Meanwhile, even before inauguration, the mayor's appointees and supporters went to work on the operation. "Everybody said there was no way that this was doable," Jeff Merritt says, and the mayor's office needed to get the ball rolling - not only to make sure that implementation would happen smoothly but also to show that the administration needed the money the mayor was seeking. "We had to make sure that Albany knew that there was urgency to do this," Merritt says. "As soon as the funding came through [the state needed to know] we were hitting the ground running and that we had everything in motion."

Current DOE Deputy Chancellor of Strategy and Policy Josh Wallack, who had worked for Bill de Blasio from 2002-06 as his legislative director, had been in the executive branch of the Bloomberg administration for several years during Mayor Bloomberg's tenure, and was running early childhood programs at the Children's Aid society at the time of the November 2013 mayoral election, immediately became a key player. From having worked on the city's successful launch-in-no-time of Mayor Bloomberg's Applied Sciences Initiative, Wallack understood what is possible when a mayor puts his full attention on a project and had an appreciation of the enormous skill and talent that is inside New York City government at all times. He immediately began thinking about what it would take to pull off the UPK effort in a very short time.

At the direction of the mayor, Wallack and others formed a pre-K task force that worked intensely to prepare a plan that could be understood by Albany and would include easilydigestible metrics-a "holistic vision for the pre-K program married to the realities of government," as Wallack puts it. Sophia Pappas at the Department of Education (who had led early childhood education in the Bloomberg administration) also worked on the plan by considering the roles all the relevant agencies would play-from the Fire Department, FDNY, to the Administration of Children's Services (ACS) and Health Department. The written output of this effort, "Ready to Launch: New York City's Implementation Plan for Free, HighQuality, Full-Day Universal Pre-Kindergarten," was published on January 27, 2014.9

The planning group then stepped back and handed the strategic planning for UPK over to a small team led by newly-appointed Deputy Mayor for Strategic Initiatives Rich Buery. Buery had had long experience in early childhood education and had led the Children's Aid Society as its President (where he had hired Josh Wallack to run early childhood programs) before signing on to work in local government as deputy mayor. His small group (Merritt calls it a "SWAT Team"), including people from the Mayor's Office of Data Analytics and DOE, set up shop across the street from City Hall on the fifth floor of 253 Broadway-the UPK launch pad. A second implementation plan, building on the first and entitled "Ready to Launch: Progress Report on Program and Space Application," was released on Feb. 25, 2014.10

\footnotetext{
9 "Ready to Launch: New York City's Implementation Plan for Free, High-Quality, Full-Day Universal Pre-Kindergarten," Office of the Mayor, New York City, January 2014.

10 "Ready to Launch: Progress Report on Program and Space Application," New York City Department of Education, Office of Early Childhood Education, February 2014.
} 
Shortly thereafter, Josh Wallack officially joined the de Blasio administration. The idea was that Buery would run the overall initiative and drive the interagency work needed to reach the city's goals. This included coordination with the Department of Education and the Administration of Children's Services agency, both of which which already had contractual relationships with community-based organizations providing pre-K services, as well as a host of other city agencies - the Department of Health and Mental Hygiene, the Department of Buildings, and the Fire Department of New York (all of which are responsible for health and safety in city-run spaces), the School Construction Authority (responsible for renovation of NYC public schools), the Department of Design and Construction (responsible for managing city capital construction projects), and others. Wallack's job was to be at DOE and manage its part of the implementation; Pappas reported to Wallack.

In mid-March 2014, Buery and de Blasio held the first of many meetings aimed at bringing all the city departments together to pull off the launch of UPK. The school year would be starting in eight months, and there was a great deal to do. Agency heads were the attendees. De Blasio kicked off the meeting - an important signal of his interest in getting UPK right. The mayor made clear that for purposes of UPK all of the agencies involved would be reporting to Deputy Mayor Buery. Buery then took over, emphasizing the crucial role of every department in the program's success. Five parallel workstreams were identified (including teacher recruitment, site identification, site approval, family outreach, and evaluation), leaders were assigned, and the collective group got to work.

Multiple levels of regular ongoing meetings provided the scaffolding and coordination needed for the UPK rollout. But Wallack insists that "number one, two, and three" in terms of importance for these meetings was the personal attention of Mayor de Blasio every week on the numbers-how many seats were available? how many kids had signed up? how many teacher vacancies still existed? The mayor constantly asked his team what else was needed to make the program a success, and was willing to get involved personally to make sure the team had the help it needed. His personal involvement in strategies for site selection, recruitment, permitting, contracting, and a host of other issues was essential. And the clear accountability of agencies to Deputy Mayor Buery allowed the team to cut through the bureaucratic challenges of inter-agency coordination that can make cross-agency initiatives difficult or impossible to implement.

The commissioners of two dozen agencies continued to meet every month as a UPK coordination group. At the director level, inter-agency working groups wore convened to direct the workstreams; workstreams, in turn, met to allow staff from different agencies to coordinate their activities. All-staff committees made sure that the work was actually getting done. And a technology group, separately focused on the development and improvement of the platform used to coordinate outreach, met weekly. All of these meetings were open; all of these meetings included an emphasis on the importance of technology. Technology was a constant. Meetings at every level were a constant. "People called me the deputy mayor of meetings," Deputy Mayor Buery jokes, "but rather than chase people down, we had all the permitting and a few other related agencies meet regularly, by the end on a daily basis, with a list of every program or site that remained unfinished." This effectively imposed deadlines on agency actions and kept the sense of urgency high. 
The timeline for the UPK rollout accelerated from this point in early February, and particularly once funding from the state was approved in late March 2014. Several processes were happening at once: Parents were applying for district school and Early Education Center pre-K spots; parents who weren't aware of UPK were being informed and assisted; the City was reviewing applications from new Early Education Centers looking to become sites for UPK programs; NYC DOE Chancellor Carmine Fariña was contacting principals to ask them to take on full-day pre-K programs; teachers were being recruited and trained; sites were being permitted and approved; the supply of spots was being matched on an ongoing basis to demand; and the city was thinking through how it was going to monitor and assess the quality of the program and evaluate its performance over time.

The technology and outreach stories behind the UPK rollout are told in detail in Sections III and IV, respectively. This section sketches the timeline for teacher recruitment and permitting.

\section{A. Recruitment}

From the moment candidate de Blasio won the Democratic primary in Sept. 2013, Department of Education employees started planning for a major operational and instructional push in the pre-K arena. They were not starting from zero. The city had established half-day (serving approximately 35,000 children) and full-day (serving approximately 20,000 children) programs in place in district schools and nonprofits running after-school programs. Many of the half-day sites would be converted to full-day pre-K, but in order to do that more teachers would be needed.

As Sophia Pappas puts it, "It was really important to build on what we had been doing, to understand what was already going on in the Pre-K program, and then to figure out how we can build on that to expand. In concrete terms, a lot of our half-day programs were turning into full day." Some existing programs opened new sites; some added seats to existing programs. During this transition period, Pappas spent a great deal of time going out to field offices to let her staff know what was about to happen. Talking to the people who actually run programs or support them was crucial, she believes. In her words, she said to them: "'This is happening. With all the work that you've done with our programs, what are people going to be excited about, what are going to be their questions, what should we build into the plans?'"

Mayor de Blasio then announced on March 25, 2014 that the city would be carrying out unprecedented recruitment and training efforts to ensure high quality pre-K teachers were available to serve students. The DOE led this workstream, placing radio ads for teachers and using its own human resources function to help recruit certified teachers who could be available in a pool from which UPK sites could select. As of mid-July, although 1,884 teachers had been hired, the sites still planned to hire 638 more. The team swiftly put together resume books (and scheduled interviews) to help Early Education Centers that were lagging in teacher recruitment. DOE also developed a pool of experienced, certified substitute teachers who would be available if enough teachers didn't get hired. (Because the city succeeded in its recruitment efforts, it ended up not relying heavily on this substitute network.) Rick Fromberg (now Senior Advisor for Public Engagement) and Alexis Confer (now Deputy 
Mayor Rich Buery's Chief of Staff) essentially set up a wing of the outreach team tasked with ensuring that every site had the teachers it needed.

Because of the conversion of half-day to full-day programs, it is difficult to say exactly how many new teachers were added on-but about a thousand teachers, Pappas thinks, were new to the system. Every UPK classroom has in it at most eighteen students with one teacher and an assistant teacher in the room; with a second assistant teacher, classrooms can have nineteen or twenty students. (Some centers have fewer students in classrooms by their own design.) It helped for recruiting purposes that the salaries of certified Early Education Center teachers were adjusted by the de Blasio administration to be closer to those for entry-level jobs in district schools than they had been, and that the Early Ed teachers were given the same professional development and coaching resources. Fifteen million dollars was added to the UPK budget for the first year to accomplish these two things. Similarly, their assessment guidelines were the same.

As Wallack puts it, "We set as a goal in the beginning that we would have one unified highquality system. What that meant is that we would hold everyone to the same high standards and would provide resources that would allow the two flavors of programs to function as a single, quality system."

Another substantive resource for UPK was the city's ties to universities. For example, the UPK team established a partnership with CUNY, building on an existing strong relationship between CUNY and the Department of Education. CUNY immediately began recruiting teachers, some completely new to the field and many others who were already teaching but without particular certification, such as the bilingual extension. Bank Street, arguably the premier early childhood education institution in the country, partnered with the DOE to run a three-day training institute for 4,000 teachers and assistants in August 2014, conveying hands-on, nitty-gritty information to teachers so as ensure that the crucial first weeks of school were a success. The city also funded four days of professional development during the school year for both district and Early Education Center teachers. And the city hired more coaches and social workers to join its existing pool, ensuring on-site direct support for teachers.

\section{B. Site Approval and Permitting}

Although many sites had housed private half-day pre-k programs or nurseries, these places needed to be converted for purposes of full-day programs. And new sites needed to be brought online. Several city departments needed to be coordinated in a massive effort to get sites inspected and permitted. As Wallack puts it, the process of inspecting and permitting sites is "a hard process." He continues: "It involves three different agencies [the Department of Buildings, Department of Health, and FDNY] that usually visit out of sequence. It's usually up to the provider [the school] to manage that process, which means it faces a lot of delay. We didn't have time for those delays."

Buery and his team worked very closely with the sites that were expanding their programs. Importantly, an intense outreach program for sites and permitting took place over the summer of 2014 in parallel with the outreach program to parents; the city actively 
worked with sites as well as parents so as to make sure the entire program was ready in time. (As Wallack puts it, "Just as we were organizing families, we were also organizing providers.") The city's Department of Design and Construction played a key role: it has its own permitting department for civic projects, and used that facility to process permits quickly for UPK sites. The sites managed their own construction, but the Department of Design and Construction set up teams to work with the managers of those sites to help them make good decisions and meet the UPK deadlines; DDC also acted as a liaison with the Department of Buildings, Department of Health, and FDNY to call them in to do inspections in the right order. Every site that the team thought was at risk of starting the school year late because of construction issues - and there were dozens - was assigned a liaison.

Wallack explains that all this outreach amounted to a campaign aimed at the UPK sites: "When you're doing outreach for an election and folks start to complain that they're getting too many phone calls, that's a sign to a field operation that you're doing a good job. We started hearing complaints from providers that they were hearing from us too much." That's when his team knew they were on the right track.

Throughout the summer of 2014, an inspection and approval "SWAT" team worked through permitting at a fast clip, using lessons learned during the Hurricane Sandy recovery and Build It Back programs. The team coordinated inspections with DDC (as well as with the Department of Buildings, Fire Department, Department of Health, and Department of Education). The Fire Department alone put twenty people on the project full-time. At the last minute, the Department of Design and Construction helped DOE finish sites before the first day of school. "There were these great stories about road builders and engineers coming into a mom-and-pop early education program, burning the midnight oil to make sure their sprinklers were installed in time," says DOE Chief Strategy Officer Josh Wallack.

All 1700 sites for the UPK program were walked through in August; staff from a variety of agencies went in with checklists for readiness and reported on what they found. Additionally, when Buery asked for an FDNY walk-through of 400 sites to check on their readiness, the FNDY Commissioner agreed to have his team do the job over a weekend. The UPK program worked on getting sites approved and ready to go throughout the summer and up until the first day of school - an almost miraculous feat of inter-agency cooperation.

On Aug. 28 Mayor de Blasio announced that the program had been successfully launched. The first day of school was a week and change away. Josh Wallack remembers: "I was tremendously excited to have hit the number of kids, and also at the same time enormously preoccupied with the details of making sure that day one went smoothly." He started to sit with the outreach team at 253 Broadway so he could be helpful and get as much information as possible as quickly as he could.

Stacey Gillett, now at Bloomberg Philanthropies, was in charge of the several rapid response centers that the city set up for the first day of school-centers that were meant to ensure people would be on site to respond to address issues that came up. Wallack says, "If a school had not opened or an Early Education Center didn't have what they needed, we would have someone within a few blocks that could get there, talk to the families, help with whatever needed doing, and perhaps relocate the families to a different center, or just let 
them know that it would be open later. We had extra sets of furniture and extra materials, and we were ready to move in. We had these stations throughout the city so we could deploy assistance quickly." Stacey Gillett remembers: "We just sat there in our war room waiting for the phones to ring," she says, "and they just didn't." She continues: "We worked around the clock until the very end, but it paid off." For Wallack, the mayor's announcement about the number of kids enrolled had been one thing, but 3:00 pm on Day One was the big moment from his perspective. "That was it," he says.

On Sept. 4, 2014, 53,230 four-year-olds began their first day of pre-kindergarten served at 1,417 sites, about $60 \%$ of them Early Education Centers with a contractual relationship with the city.

$++++++++++++++++++++++++++++++++++++++++++++++$

The city pivoted to Year 2 . The city technologists absorbed the lessons they had learned and continued to improve the systems that would be needed with the addition of 20,000 UPK seats (for a total of 73,000 enrolled) for the 2015-16 school year. City Hall continued to coordinate the elaborate interagency work need for UPK to continue to succeed. And formal and informal evaluation processes moved ahead. The city might not know for years what effect UPK had had on children's lives, but it already knew that attendance-a good proxy for parental happiness with UPK-had been strong, with $90 \%$ attendance overall as of December 2014.

\section{The Data Story}

The technology story of the UPK rollout includes several novel elements. Chief among them was the effort to merge disparate data sources in order to figure out which nonduplicative households in New York City might include four-year-olds and thus were good candidates to hear about UPK. Data scientists call this "entity resolution," and it was an enormous ongoing job for the city during the summer of 2014. The "golden records" produced by this work were then loaded into Briana-the campaign-management platform relied on by the outreach function-so that outreach workers wouldn't be inadvertently alienating families through multiple contacts based on close-but-not-identical data records.

The data team had to be creative in finding the families of four-year-olds in the first place; before the spring of 2014, the city had not been focusing on targeting this demographic. Now these people were going to be asked to voluntarily sign up for a new city program. Nick O'Brien, now Director of Public Affairs in the Mayor's Office of Data Analytics, says microtargeting was essential: "What modern political campaigns taught us was that you can micro target and that provides value and if you want to do this right, that's where you need to go. We wanted to get specific on finding individuals and targeting them with specific outreach, answering their specific questions and actually facilitating that process."

And the de-duped "golden records" representing those families in the Briana campaignmanagement system were a crucial element of the success of the UPK rollout. As Sohaib Hasan, the former Mayor's Office of Data Analytics data scientist who generated the "golden records" for the rollout puts it, "It's like when you get letters from Optimum or Time Warner 
saying 'Sign up for a 3-for-1 package.' If you get three a week, it just turns you off of it altogether. You say to yourself, 'Oh, I was considering it, but now go to hell. I'm not signing up for any of your stuff." The city could not afford to irritate the people it needed to volunteer for UPK by calling them multiple times-that would be a mistake from both a customer service perspective and a using-tax-dollars-wisely perspective-and it wanted to be able to swiftly help those people down the path towards successful enrollment. To do that the list needed to be clean.

A second tech-related element was the effort to repurpose existing city databases and systems to handle the new UPK program, from permitting and inspections to enrollment and teacher certification. It's fair to say that this effort remains a work in progress. The city intentionally decided to work with what it had and to revise systems only as needed, an approach that allowed it to make agile, problem-solving decisions on the fly.

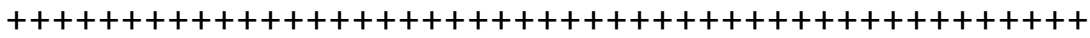

It was clear from the outset that the city's existing data systems would need substantial work in order to inform, track, and report on these processes. The city had a billing system it called Pre-Kids that it had used to pay Early Education Centers for their services. It had a post-enrollment tracking system called ATS for children and parents who had begun attending school at these centers. And it had an online portal called SEM for parents to use to express interest in pre-kindergarten programs within district schools (and be matched to those programs). But the city didn't know which families had four-year-olds or what families were interested in before the enrollment moment. Nor did it have an application and matching system for Early Education Centers.

The city held an all-day "Tech 4 UPK" brainstorming session at the Made in New York Media Center in DUMBO on April 10, 2014 that brought together more than a dozen city departments and representatives from a long list of private-sector tech companies. The session was aimed at mapping out the interrelated processes that would accompany UPK and assessing the tech needs that would be associated with those processes. It was also designed to make sure that people from different agencies who didn't know one another would meet and would all be on the same page with respect to the centrality of technology to UPK's success. The city knew that a major technology blunder might undermine the entire meaning of UPK - again, healthcare.gov provided the mental model-and wanted to make sure everyone working on the project understood the interrelationships among the city tech systems involved in site selection, outreach, enrollment, recruitment, permitting, and evaluation. The gathered group worked through goal-setting and mapped out the complex processes involved in site selection, student enrollment, and monitoring/evaluation.

Following that meeting, the city decided, in Merritt's words, that "the essential thing we couldn't do anything without was the platform for outreach." The city needed to figure out where the four-year-olds were so that it could let their parents know about the UPK opportunities convenient for them. And the city needed to track, in detail, its outreach efforts. To manage and coordinate this crucial element of the UPK launch, the city would need a platform similar to those used in grassroots mobilizing or political campaigns. 
The answer, built side-by-side by Avanade and DoITT employees in just nine days following the granting by Microsoft of free licenses to its Dynamics customer relationships management software, was a customized version of the Dynamics platform. City employees called the resulting platform Briana after the charming pre-kindergartner who had been featured in the media campaign for UPK. The city immediately loaded into Briana data about the short list of parents who had already expressed an interest in pre-kindergarten by way of the Pre-Kids system.

But how was the city going to reach the rest of the likely parents?

As Nick O'Brien puts it, "The challenge is that four year olds don't touch databases a whole lot." But the city needed to quickly identify households that were likely to include four-yearolds. During the early spring of 2014, the city obtained commercial data from Experian based on consumer transactions that included names, addresses, and phone numbers of people that Experian believed were parents with four-year-olds. HHS Connect, a mayor's office case management data aggregation system that aims to "increase data sharing capabilities among [the eight health-related] city agencies to view clients holistically, tailor services to their specific needs and identify at-risk persons in a timely fashion," already had relationships with the health-related city agencies and was able to go to them and ask their permission to use data that might be relevant. (Nick O'Brien points out that having this single point of contact at HHS-Connect was essential for MODA to do its work.) HHS-Connect had then done its own "entity resolution" on this data, removing duplicates and using fuzzy matching to account for human error in inputting the data.

Importantly, before any HHS-Connect data was handed over to the Mayor's Office of Data Analytics in connection with the UPK rollout, all data that might indicate the nature of the interaction between the household and the city had been removed. Nick O'Brien: "The agreement we made with them was that they weren't going to tell us why the people were in the system." All MODA got from HHS-Connect was a set of names, addresses, and phone numbers-essentially, "here's the name of somebody we believe has a four-year-old," in O'Brien's words. With the addresses, MODA could generate the Building Identification Numbers, or BINs, associated with these records. (BINs are the unique identifiers assigned by the Department of Buildings to the approximately one million buildings in the city. Lauren Talbot of MODA developed an enhancement to the city's geocoder that allows any address in the city to be geocoded easily and thus matched to a BIN, even if the address has been typed in messily.)

Sohaib Hasan, at the time a MODA analyst, took the Experian data and matched it to the HHS-Connect data (total of 100,000 records, 50,000 in each) using SAS Data Flux-a product that implements data science entity resolution techniques that allow for human error and fuzzy matching. Both data sets were clean-meaning that the data had been corrected, deduped, and completed to the extent possible-but there was very little overlap between the two populations of households identified by the two sources. He thought, "Maybe it's okay. Maybe for whatever reason these datasets encompass different universes." He assigned unique household IDs to the records produced by this merge. 
By early June, after additional data sets came in (Pre-Kids, containing parental expressions of interest in UPK; ATS, containing school confirmation of parental registrations; and SEMs, the district school application and matching interface) Hasan was able to use the unique household IDs and the children's names contained in these various data sources to generate a unique child ID. Those records (without the children's names) were loaded into Briana. The outreach team could start making phone calls. They were anxious to do so: as Nick O'Brien puts it, "They had phones, they had people, they wanted to get started."

The next step was to update that data, first with Department of Mental Health birth records and then, on an ongoing basis, with the additions continually being generated by the agencies and Experian. Hasan kept working on matching/de-duping the pool of data generated by these combined data sets, constantly improving the quality of the data and updating Briana every day.

Things went wrong; the new data was triggering the creation of new household IDs, meaning that each household had a unique and correct household ID but the ID kept changing every time an update was added. Hasan had to build a front-end piece of software that would run before Data Flux kicked in, ensuring that the household ID stayed constant. The updates often wouldn't load because they included special characters that Data Flux couldn't handle. "[Algorithms] just throw their hands up in the air and say, 'I'm not doing this.' Any little thing makes them go crazy," Hasan says.

All of this was hard (Hasan says he was Googling around to figure out what to do; he had no experience with Data Flux) but the hardest part, Hasan says, "was getting all of the information in the right place so that the tool [Briana], the CRM tool that sits in the front of all this that the volunteers actually look at, had all the fields that they needed in the right place. It was a lot of data manipulation," he says. He was able to order the data so that more likely households would be called first-for example, if a household was on the list only because a child had been born in NYC, but appeared in no other data sources, it was less likely to still be the home of a four-year-old. Many people are born in New York but don't stay past their fourth birthday.

There was no time to go through a standard development cycle with this work. Hasan did all his manipulation directly by using SAS Data Flux and his own techniques on the secure Data Bridge warehouse maintained by DoITT that brings data together from all over the city. He was doing all the development and testing himself while working directly in the production environment (the actual customer-facing transactional systems of the city) rather than in an isolated development context. Hasan managed to get the updates routinized and working before he left the city's employ at the end of summer 2014. By the end, Briana contained about 150,000 unique golden records. "[UPK] was not only my professional life. That was my entire life, this project," Hasan says. "It was pretty brutal." He became responsible for generating the four or five daily reports the city urgently needed as well as ensuring that Briana's records continued to be golden, and resources were inadequate: "There were a lot of fraught moments and long weekends," Hasan says.

In addition to producing golden records for outreach purposes, MODA ensured that the records and numbers generated by the city's various different enrollment systems were 
reliable-equally golden. As Nick O'Brien puts it, "The situation I don't want to get into is the city says that it has 53,000 students and then 30,000 students show up because we were doing the matching process incorrectly." That didn't happen.

Parents could sign up through different systems: through the Administration for Children's Services (handling both Head Start and other systems), though Early Education Centers themselves, which fed into the Pre-Kids system administered by the Department of Education, or through district school enrollment in the SEMs or ATS systems, both also run by DOE. In fact, the same parent could apply for multiple different programs. Data coming from these disparate systems needed to be unified and de-duped so that the mayor and his team would know how enrollment was actually going over the summer.

MODA carried out a similar data science process, using Data Flux, to match data from all of these systems so that it could report to the city, in Nick O'Brien's words, "We believe this student is the same as that student; we're going to count them once." And it worked: "We could actually have a reliable number as we moved towards the start of school," O'Brien says, by generating numbers for seats versus capacity, broken down by borough, school districts, and eventually individual schools.

There are at least three lessons to be learned from the golden records work in New York during the summer of 2014. The first is policy-based: The city was able to find households that were likely to include four-year-olds by combining city and commercial databases in such a way that it had the capacity to micro-target those addresses. The UPK rollout was a campaign, and micro-targeting was essential to its success. At the same time, the administration was proactively paying deep attention to the privacy concerns that might have been triggered by micro-targeting. The people working with Briana data never knew why the city had data about particular households. They didn't need to know.

The second lesson is about effectiveness: by doing matching and merging using data science techniques, MODA made it possible to know reliably and in real time how many unique students were signing up for the different flavors of schools in their many locations. Without this information the city would have been operating in the dark long after the start of school.

The third lesson is operational: Staff up. Get a number of data people on board, people who can write code as well as manipulate Excel spreadsheets. Nick O'Brien says that data science is still in its infancy when it comes to local government: "We're still in that early phase where it is based on champions that are in an agency, have a mix of technical savvy and an ability to hack the bureaucracy, and know a lot of people so they have credibility within their agencies. It's not at the point yet where this is something people believe they have to have." New York is a leader in this area, but even in New York City data science may be insufficiently standardized, respected, and persistent in individual departments. Consultants are useful but they are extremely expensive; bringing in adequate coding resources in-house is essential.

For many reasons, all of this data work needed to happen extraordinarily quickly over the summer of 2014. A cautious bureaucrat might have wanted to test pilots over five years, but 
that would not have worked politically. UPK would never have taken on an air of inevitability if the city had taken years to launch the program.

The systems story behind the UPK rollout is distinct from the "golden records" story.

\section{A. The Disparate Systems at DOE}

The systems in place at the time of the UPK rollout were historically independent and largely special-purpose. A great deal of work was done to ensure that accurate real-time numbers were available to project managers and the mayor's office. The agility, flexibility, and professionalism of city employees made this accuracy possible; the city chose to work with what it had and iterate on the fly in response to problems that came up. Although difficulties remain, this approach paid off.

As of June 2014, the city had a number of channels for enrollment that did not interoperate and had not been designed to handle an enormous expansion of prekindergarten.

First, the Department of Education had been using a system called Pre-Kids for paying the half-day Early Education Centers that existed before the 2014 UPK rollout. But it was designed to manage vendors as vendors - their budgets, expenditure reporting, billing and payment processes. It was not designed to handle enrollment in a fast-moving, high-volume program.

Pre-Kids was swiftly repurposed to take in enrollment information from Early Education Centers, but, as Lucas Koehler puts it, "There was no way of knowing if a draft enrollment in one center was the same student as a draft enrollment in another center." So when the city needed to know how many children were enrolled in a particular center, the system couldn't help. MODA helped solve this problem, as described above. The system was also clumsy to use, so the outreach team did a great deal of data entry on behalf of the Early Education Centers. The all-hands-on-deck nature of the UPK rollout, and the ambitious targets the city had set, contributed to an atmosphere in which the city was willing to do anything it could to get the Early Education Centers up and running.

Pre-Kids was collecting enrollment information from the vendors, and then when students actually enrolled those records were loaded into a system called Automate the Schools, or ATS, which covers both district schools and Early Education Centers-"the ultimate destination of the student-level data," according to Lucas Koehler. Additionally, ACS contracts for Head Start programs under the UPK program, and those enrollment figures were kept in a separate database. MODA helped merge the Pre-Kids, ATS, and ACS databases to eliminate duplicates, as described above.

In parallel, as of June 2014 new Early Education Centers were applying in response to the city's RFP for three-year contracts with two one-year renewal options, but all of that data was being managed via an offline process: Excel spreadsheets were being used to collect and record applicant-level data about the RFP process, the scores given to those new centers, and award decisions. Centers from the previous year were managed via a separate Excel 
spreadsheet. So when the city needed to know how many Early Education Center seats it had ready to open in September, those two enormous spreadsheets had to be merged somehow.

A top priority was to move those spreadsheets into Access-which meant building an Access structure, cleaning the data, and loading it. That, in turn, meant taking time away from the daily fire drills and requests for immediate reports, but it had to be done. Lucas Koehler's entire team took three days in August and created the Access setup. By mid August the city was feeling confident that it had a grip on how many Early Education Center programs and seats it was working with. (The district schools were tracked by a separate system.)

Meanwhile, a state work system called Aspire needed to be used to keep track of teacher certification status for the Early Education Centers; the city would need to use this system to match teachers with the classes that the teachers were teaching and to know how many students are being taught by certified teachers. (The state grant reimburses the city differently depending on whether a student is taught by a certified teacher.) ATS and Aspire had to communicate in order for the city to have confidence that it was telling the state about verified, real enrollments in classrooms with certified teachers. And Aspire needed to track professional progress towards certification and attendance at development courses. As of June 2014, the city had yet to get 5000 Early Education Center people into Aspire (including directors and assistant teachers). And Aspire covered only Early Education Centers, not district schools. District schools are supported by the existing professional development certification programs run by the DOE.

To further complicate things, some of the Early Education Center seats were funded by DOE contracts and some by ACS contracts (more focused on low-income families than the DOE contracts), and those contracts had different requirements. ACS does not report to DOE with respect to these expectations. In parallel, the district school enrollment system, called SEMs, was supporting the district school application and matching process for the district schools but not for the Early Education centers.

\section{B. The Problem of Permitting}

Many agencies needed to cooperate in order for UPK sites to obtain the necessary health and safety permits to open and serve children - chief among them the Department of Buildings, FDNY, and the Department of Health and Mental Hygiene-and the Division of Contracting and Procurement inside DOE was responsible for ensuring that that permitting happened on schedule. The Mayor's Office of Contract Services, the New York City Department of Investigation, and the First Deputy Mayor's office (in the person of Vanessa Champion) all played critical roles in this process. But many of these departments track buildings and spaces in New York City using independent (and differently organized) systems. So although the Department of Buildings, FDNY, and the Department of Health and Mental Hygiene were working as quickly as they could to expedite permission for pre-K sites during the summer of 2014, they didn't have a single, common place in which information about how a particular pre-K site was moving through the permitting process could be stored. 
Although initially the departments attempted to work around this problem by emailing around Excel spreadsheets to be updated, that proved to be a clumsy system. The departments already had their own processes, and working with the spreadsheets meant that they had to update information in two places. Additionally, the spreadsheets were difficult to decipher. (Lesson learned: updating functions that depend on city employees doing the same job twice, the second time in a hard-to-understand and unfamiliar system, are doomed.)

Permitting in the end was driven by a single person visiting agencies one by one and manually updating a massive spreadsheet to show the progress of UPK sites against permitting requirements. Good-willed representatives of those agencies also joined together in innumerable conference calls to track the progress of every pre-K site that was having trouble navigating the permitting process. As Stacey Gillett, former Executive Director for Strategy and Sustainability at the Department of Education, puts it: "Technology did not help us in the least [with permitting]. It was communication that was able to help us." The quality of inter-agency collaboration associated with this aspect of the UPK launch was extraordinary: "Everybody really had this great feeling of 'We're all in this together,'" Gillett says. The city was doing everything it could to get those sites up and running.

Technology did play a role when it came to the final strokes in the permitting area. The city had to figure out how to deploy squads of volunteers to walk through Early Education Centers to make the final checks, and there was a short period of time allotted for these last walkthroughs. The outreach team included people who were great at mapping because of their campaigning background. They used Google Maps to print out routes that were then given to every walker. The city was then able, in effect, to say, "Here's where you're going, here's the order of centers that you'll visit, and here's the most direct route." The energy of modern-day campaign-style tactics directly contributed to the city's ability to provide this basic government safety-related service. The effort paid off: as of December 2014, just two of the 1700 programs had been forced by the city to withdraw from UPK because of health and safety issues.

As of April 2015, improvements described in Section $\mathbf{V}$ are being made to these disparate systems for Year Two. The city survived Year One by empowering city employees to act with agency, energy, and agility to make existing systems work-an all-hands-on-deck story in the context of technology. Most importantly, 53,250 families were comfortable throughout the fall term of 2014 leaving their young children in the care of new city UPK programs.

\section{The Outreach Story}

Making parents aware that having access to a free pre-K program is part of being a New Yorker posed a substantial barrier to success. A few weeks after Josh Wallack officially joined the de Blasio administration, he says, he was "very lucky" that he and Intergovernmental Affairs Director Emma Wolfe found campaign veteran Rick Fromberg and hired him to "run a real campaign, an outreach campaign to reach out into neighborhoods and make sure that the children that we wanted to take advantage of this program took advantage of it." Fromberg joined the administration as Senior Advisor, Pre-K for All, in late March 2014, and immediately set up a team of volunteers and city employees. The administration team always knew, according to Fromberg, that "Pre-K for All was going to be a huge logistical challenge." 
He continues: "I think we always believed that tens of thousands of families would see the great benefit for free, full day, high quality pre-k, but we knew that engaging them and getting to them would require a herculean effort."

Fromberg believes that the way in which outreach was done for UPK in the City of New York combined campaign techniques with service delivery in a way that had never happened before. He also believes other cities can learn from the lessons NYC has picked up. "There are basic, good organizing principles that permeate from community advocacy campaigns to political campaigns, to organizing drives, to social justice movements," he said. "But those basic organizing principles that make a difference and get results hadn't really been applied to government services in the same way." With sufficient resources and focus-working in a defined structure where people know who they report to and what the goal is-he believes a city outreach team can address nearly every pre-first-day-of-school UPK challenge a family may face.

As Nick O'Brien puts it, "The way the UPK effort was framed by Deputy Mayor Buery was really smart-it's voluntary. We are trying to get people to voluntarily take an action and that's what you try to do in a campaign." And Alexis Confer, who came into the administration as Outreach Director for the UPK effort, saw the parallels clearly: she says she told Rick Fromberg she was "willing to put up the Obama-style field operation." Confer knew what she was talking about: She had been State Deputy Field Director for the Obama 2012 operations in Philadelphia, responsible for eight regional field directors, ninety field organizers, and hundreds of volunteers. "Respect, empower, and include" were their watchwords. As soon as she arrived, she began training large groups of non-profits about the UPK plan. "We were literally building the plane while flying it," she says. The energy in the Outreach Team, she says, was "incredible." An immediate need: more administrative staff.

Stacey Gillett notes that urging people to participate in the UPK rollout was in many ways a more difficult ask than a political campaign: "It's more difficult than 'Who are you going to vote for?' because it's about safety, and your child's life, and these are things that take much more of your time and thought. It's so personal." Fromberg is particularly proud that the outreach function he led during Year 1 went out to families directly rather than waiting for families to come to the government. To get this done, he says, "We layered in really great people who knew their communities, who could help the family navigate a challenging process, and who could be innovative in finding families in the first place." As these "Family Engagement Specialists" (outreach coordinators) built relationships in their neighborhoods, parents volunteered to help, too.

This outreach function had the benefit of a good deal of general media awareness. Through a partnership with the New York City Housing Authority, the Department of Education sent more than 3000 eligible families in public housing both direct mailings and automated calls. Carefully targeted paid media, including ads outdoors, over the radio, inside subway cars, on buses, and in community newspapers, was combined with similarly targeted digital advertising. With the help of Mobile Commons, the outreach team ran a targeted texting campaign. Ads were placed on Pandora. The team did everything it could to target media so that it would reach parents in places with lower enrollment rates. "We married 
some of that traditional community organizing with the technology-focused targeting," Fromberg said.

It worked, according to Fromberg. "No matter who were are, whether you were the parent of a four-year-old or you weren't, you were hearing about the benefits of pre-K," Fromberg said. "If anybody didn't sign up, we didn't want it to be because they hadn't heard of UPK," he continues. Confer says the city's approach to this task represented a major change in the activity of government. "In order to run this kind of a program in another city, you have to change the way government breaks down walls for constituents and citizens. You say, 'We're going to help you access these services.' Otherwise, you're under-serving the city. If you don't change your way of working, only the people who are the most vocal or already know the most about their community will actually get those services."

But this awareness needed to be converted into actual kids in actual seats.

Applications for district school pre-K programs were due April 23, 2014, but the neighborhood early education centers were taking applications steadily until the first day of school. By the time Mayor de Blasio on May 30, 2014 announced that there would be more than ten thousand new full-day pre-K seats at the Early Education Centers, Fromberg's team was ready to contact parents in person, combining the traditional worlds of community organizing and government service delivery with cutting-edge, data-driven campaigning.

Between June 1 and the first day of school, dozens of outreach workers put in six-day weeks across the five boroughs attending events, talking to families, and ensuring that more than 520,000 New Yorkers heard about UPK via phone calls, emails, or texts. The numbers are impressive: the thirty-five leading outreach workers collectively attended 500 events, spoke to 11,000 eligible families, and delivered 1.2 million texts, emails, and phone calls.

Their work was managed and recorded using Briana, which, beginning in June 2014, was deployed to produce multiple regular reports for the mayor and his team. And as the city learned more through its extensive outreach to eligible families (would they prefer a district school or early childhood education center? what locations, either close to home or along a parent's commute, were most convenient?), the data driving Briana became richer. As of July 20,2014 , the Briana database included 150,000 records.

Leading Brooklyn outreach coordinator and current Director of Partnerships Jasmine Fernandez, using both data and her own experience, went to the streets. From the work done by MODA as well as data showing historic application patterns, the outreach team had maps of anticipated demand for pre-K seats. Like many public employees involved in the outreach program, Fernandez had personal ties to the communities she was canvassing and spoke the parents' native language: she grew up in East New York and had most recently been working in Haiti setting up a school before going to work with Fromberg on the UPK initiative. Fernandez and dozens of her fellow outreach workers reached parents through word of mouth, through fliers, meeting them wherever they spent their Saturdays, whether at playgrounds or in laundromats or nail salons. "We were thinking, 'What are the biggest hair salons?'" Fernandez says. "That's where we need to be." 
Fernandez and the others went to family-oriented public events as well, making appearances at churches, summer block parties, and a huge variety of parades, including the Hong Kong Dragon Boat Festival and the Fourth of July parade on Staten Island. At the events, public employees collected interested parents' phone numbers and addresses. Back in the office, they checked the parents' local options in the DOE databases and followed up with phone calls-not just checking on enrollment status but also offering assistance in completing the process.

Fromberg and his team stayed in similarly close touch with the Early Education Centers, monitoring the seats available and ensuring that programs were actually going to happen. If an Early Education Center was struggling to fill its seats during the late summer of 2014, Fromberg's outreach team "adopted" them and called families in the area or walked with program staffers through their adjacent neighborhoods. Alexis Confer, now Deputy Mayor Buery's chief of staff, hired case managers who helped struggling Early Education Centers get their data into the city's systems. These staff members also coordinated with DOE, helped with marketing and events, helped new centers hire teachers, made fistfuls of recommendations to new directors, and generally nudged, cajoled, and encouraged their charges to be ready in all ways by the first day of school. "Towards the end," she says, "we were calling Early Education Centers constantly. We were physically going to their offices and inputting data for them."

This outreach balance between supply (is the site ready to serve students?) and demand (do parents know about UPK?) was essential to the program's success. As Merritt puts it, "'If you had empty seats, it meant that people didn't actually want pre-K, which would undermine the whole premise," Merritt says. "If you had all these parents interested and seats weren't available, it would also fall apart." Stacy Gillett puts it this way: "If we're going to put money into a city service, and we're going to offer that service, we want everybody who is possibly eligible for it to use it."

Outreach was not limited to media and street fairs. Deputy Mayor Buery engaged Immigrant Affairs to support outreach to immigrant communities and the Department of Homeless Services to facilitate outreach through their shelters. As Jeff Merritt puts it, "Every agency has a constituency, and we needed to make sure that every agency was doing outreach, however it made sense for them, whether it was by displaying materials about UPK at their offices or using their properties as places to post information."

Robo-calls from the mayor, the DOE chancellor, or neighbors were used to ask recipients to press one if they wanted additional information about UPK. The outreach team then made sure that those callers got a call back within a day, and often checked in on parents they had met via text message.

A dedicated team of nineteen pre-K specialists was folded into the 311 system, so that questions about UPK could be expertly answered on the spot-and parents could apply over the phone with the help of 311. This use of 311 as an additional channel for implementation of enrollment marks a milestone in the evolution of 311 into a platform for many forms of engagement with and among citizens. 
By texting 877-877, citizens could receive information about UPK on their phones. If they had a smartphone, a mobile school-finder tool allowed parents to find the best program location for their child; they could then apply via the UPK online site. Parents were surprised that the city of New York was making such an effort to help them. The Early Education Centers felt the same way. "A lot of the Early Ed directors said to us they had never felt so supported," says Alexis Confer. "They really loved their case manager, the specialist they worked with."

Whenever the relentless pace threatened to derail the effort, Fernandez says, "We had to just regroup and say, 'okay, why are you here? Do you remember your pre-k teacher'?" Fernandez said. "That really puts things into perspective. For all of us it was very personal, and I think that was really what drove us." Stacey Gillett remembers how exciting it was to have young "campaign people" working with experienced DOE educators. "There was an agility and an urgency to the campaign people that is a totally different skill set than what you have in your traditional city government worker. It was an interesting and critical skill to throw into the mix."

Perhaps the most interesting element of the outreach campaign—one that organized new teaching sites as well as families-was the different view it provides of citizen engagement. In addition to measuring what government services citizens request, the de Blasio team has tried to reach New Yorkers. Here is Wallack's view: "This administration is reaching out proactively to citizens informing them about the services that are available and trying to engage them, whether that's for a municipal ID, pre-kindergarten, the Earned Income Tax Credit campaign [free tax preparation services], or food stamps. There's a lot of work going on to reach out to people to let them know, 'This is on offer. We believe this can help you, and your family, and your friends. We want to tell you about it. We want to make it accessible to you and inviting to you and easy for you to use,' and that's going to help all of us. I think that's a very exciting strand of the work and I think people in this administration bring in as much analytical rigor to that as the last administration did to problem solving,"

All of this outreach was data-driven, says Alexis Confer: "I do think looking at outreach with a data-driven, metrics-driven, targeted focus is key. I hope we never lose that. You can't just throw out a blanket of outreach." But the data was deployed with a human touch. As she puts it: "How do you get the Early Education Centers to be in line? It takes developing a relationship. It takes showing them what supports are available to them. Making them feel like they're owning a piece of the process, as opposed to just hearing information top down. It's that buy-in factor. It goes back to when I talked about the Obama campaign earlier. The empowerment element. All good development that you see, whether it's internationally or nationally, is when a community feels bought into it. The centers needed to be bought into the vision of "Pre-K For All and feel like it was exciting to be a part of it."

\section{Year Two}

The first day of school in September 2014 represented an extraordinary milestone for New York City: tens of thousands of four-year-olds had been placed in a full-day pre-K program for the first time. Now Year Two poses new challenges. More than 18,000 additional seats will be opened up in a context in which demand is already very high: On the first day of 
enrollment for Year Two, 22,000 families applied. ${ }^{11}$ The expansion of the program is, in Wallack's words, "helping to focus everyone's attention." As of April 2015, the city planned to open 190 new sites for Year Two (about 130 Early Education Centers and 60 district schools that are new to pre-K), with many more coming in through a new RFP launching in mid-2015. Both Buery and the Mayor continue to be very focused on the ambitious metrics for the program.

As of the time this case study was drafted, the application period was still running for Year Two; demand is running high, making it clear that although everyone will be offered a seat it may not be in a parent's top choice of location. The bottom line: it will be exceptionally difficult to ensure that there are enough quality seats where families who need them actually live, or where convenient transportation will allow those families to take advantage of those seats. As Deputy Mayor Rich Buery puts it: "In some ways the second year challenge will be even more difficult than the first year challenge." The geographic challenge is also extraordinarily acute when it comes to space acquisition: in Year One, the city needed more seats in every area of the city, but in Year Two there will be a need for more seats in both lowincome areas (in which Early Education Centers and qualified directors and teachers may not now be present) and high-rent areas (in which qualified teachers could establish first-rate programs but where finding reasonably-priced space will be extraordinarily difficult). In Year One, the city benefited from an existing network of early education centers that could be converted to full-day pre-K sites. (Not all Year One sites were pre-existing; Year One included a mix of programs that were not part of the pre-K system but that were part of public or private child care systems, were part of Head Start programs, or were brand new programs.) Now that many of these existing sites have already been folded into the program, in order to reach its expansion goals for Year Two the city will continue to need to identify, permit, and help staff new sites from the ground up-a daunting task in any context, but particularly challenging when there is so little time to do the work.

The limiting resources may not be just money: there are only so many qualified education directors and teachers in the city, and the city may have already reached and included many of them in its UPK program.

On the other hand, Year Two will benefit from a streamlined, unified application portal for parents hoping to enroll in either Early Education Centers or district schools. To get this done, the city rolled the Pre-Kids Early Education Center enrollment system behind the interface presented by the former SEMS system, which used to support applications and matching for district schools only. Parents applying through this portal may apply to multiple schools but will be matched to just one. (After children actually show up on the first day of school, the ATS "system of record" is updated; it is the ATS system that informs the city's actual payment to vendors.) The city expects that the two flavors of schools will be treated essentially equally for assessment and professional development purposes.

The net public effect of this co-branding, the city hopes, will be that Early Education Centers are perceived as an equal alternative to public school programs. Early Education Center teacher salaries have already been increased, thanks to \$15 million in funding

\footnotetext{
${ }^{11} \mathrm{http}: / / w w w 1 . n y c . g o v / o f f i c e-o f-t h e-m a y o r / n e w s / 176-15 /$ transcript-mayor-de-blasio-22-000-families-apply-pre-k-first-day,
} 
earmarked for this purpose. "We're building to a system where you will be able to walk in wherever-a school or an Early Ed center-and it will be the same," says Josh Wallack. Greater centralization and standardization will allow for better data-driven understanding as to how pre-K is affecting students as they go through the system.

DOE has many plans. It wants to showcase great Early Education Center teachers. Recognition could be a great motivator, says Pappas. And more Early Ed teachers will be certified, thanks to a partnership with CUNY that will allow about four hundred teachers to get early childhood certification or bilingual or special education certification extensions by September of 2015. Additionally, DOE has built up its support structure for teachers: "We now have 100 social workers; we used to have 60. We had 40 instructional coordinators; now we have 70, and we're going to increase even more," says Pappas. DOE is focused on improving both classroom instruction and family engagement through data-based decision making, evidence-based practices, and research about how young children learn best to make the most of this historic opportunity for children, families, and communities across our city.

At the same time, there are differences among Early Education Centers (and district schools) that will be important to parents and will need to be maintained even as the centers are being made a standard part of the education system. As Stacey Gillett puts it, "There needs to be a lot of work to educate people on the [Early Education Centers] as being of equivalent quality to the district schools, but I think one of the things that the [Early Education Centers] have going for them. . . is that they are very different from one another. And that's a selling point for families. The challenge is to articulate that there are common quality standards, but also that there are things that make them unique."

A key remaining challenge: how should DOE prioritize its investments in curriculum, tools, and support structures so as to ensure that the city's UPK program is as high-quality as possible? What should those one hundred instructional coaches be doing with their time? The scale of the NYC UPK program is so much greater than anything attempted elsewhere that quality assurance guidance from "peers" doesn't really exist. For Year Two, New York City has to make these decisions on its own, in a very limited timeframe.

On an institutional level, UPK will need eventually to transition from an urgent, all-handson-deck initiative to an ongoing program within traditional city channels. Year Two, however, is still "urgent" in most ways. Deputy Mayor Rich Buery is still involved in ensuring the mayoral prioritization of this project remains visible, and all the work of cross-agency collaboration and accountability continues. The outreach team has not disbanded and began earlier in 2015 than in 2014 to ramp up its work of reaching families directly. The highlymanual project of inter-agency permitting coordination continues, with City Hall driving the difficult work involved in identifying new sites (in partnership with DOE, the School Construction Authority, and the Department of Design and Construction).

Meanwhile, DOE is continuing its major role in UPK, focusing on spearheading the selection of UPK programs, finding additional facilities, getting the programs stood up in collaboration with other agencies, and administering those programs. To get this done, DOE has staffed up substantially, with a new operationally-experienced chief of staff under Pappas to whom the complex operational elements of UPK report and an expanded data team. 
On the technical side, in addition to the single enrollment portal and matching process for families, DOE plans to use Aspire (the state workforce registry) to drive more targeted professional development of the 5000 Early Education Center educators now represented in that data system. The data team within DOE, led by David Price and Lucas Koehler, is building its capacity to collect and manage data about what internal evaluators see in UPK classrooms, and has made a major effort to predict enrollment levels for Year Two in different city neighborhoods. Eventually, the SEMs system will be part of a unified, integrated platform that includes the lifecycle of UPK transactional data: applications from both parents and education centers, enrollment, site readiness, attendance, and information that can inform evaluations. David Price, who was integral in addressing many of the Year One systems issues, now works for Josh Wallack and alongside Lucas Koehler. Price, who like many members of the UPK team had formative experiences during the Sandy recovery, is now in charge of revamping the UPK data systems. The city is trying to move from multiple systems to far fewer, with the hope that in three or four years there will be a single integrated system.

On the outreach side of the operation, MODA is evaluating which sources of data were most valuable and seeing "which resources gave us garbage," says Nick O'Brien, "so we're not spending hours calling numbers that don't exist or don't have four-year-olds or trigger 'How'd you get my number?'" And the city is sharpening its analysis of where seats are needed, allowing it to be much more focused in its outreach to sites and schools.

\section{A. Evaluation}

Evaluation of the quality of the pre-K experience is under way. Evaluation was baked in from the beginning. Josh Wallack says firmly that "The moment [Deputy Mayor] Rich [Buery] walked in the door, he said, 'One other thing we have to do right away is get an evaluation going."

Deputy Mayor Buery expects mixed results. "What we will have is a platform to improve upon," he says, underscoring the importance of starting big and then working on quality rather than starting modestly and having to make a case for scale. "We all know that good quality will lead to results, so all we have to do is figure out how to deliver quality at scale, and that's big work, ongoing work that we're going to continue to struggle with for years," he says.

Inside and outside groups are carrying out evaluation. Internally, one of the DOE's seventy instructional coaches visits every UPK site at least once before delivering a qualitative assessment; a dedicated evaluation team will assess the district schools, charter schools, and Early Education Centers; and another DOE team is leading an evaluation of child-teacher interactions and classroom environments (thus reducing the Department's dependence on external consultants). The DOE's newly expanded data team is collecting information from these visits, social worker visits, and class and environmental assessments for purposes of combined analytics, and the EDC's Center for Economic Transformation is evaluating the program's execution and use of technology. 
Externally, a group of third party consulting firms including Westat and Metis won a $\$ 2$ million city bid for the official evaluation of implementation and outcomes. Their study uses a sample size of 200 sites and is intended to be useful to other cities. An NYU research group will also evaluate the program, without cost to the City.

Wallack, who served for more than six years in the Bloomberg administration, is focused on quality: "What you have is a set of teacher evaluations, a set of annual scores on nationally marked instruments. You have data from visits of instructional coaches and social workers. You have some data on health and safety. All of this has to be brought together in a way that moves people to action, and I think that's the challenge for us." He continues: "I find this administration to be every bit as focused on data as the last one. This one, the de Blasio administration, sets different goals because of the broader, philosophical underpinning of the administration. I find that the rigor is the same, the push for results is the same, and the pragmatic approach to what you're learning from the data and what you have to do to adjust to it is the same."

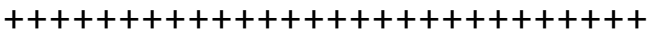

\section{Conclusion}

The UPK rollout story for Year One was a success from many points of view, with the low fall-off rate for both parents and schools (just eleven sites have withdrawn from the UPK program) serving as a key-if preliminary-indicator of interest and quality. Many of the traditional elements of a well-executed local government program were in place in New York City to make this happen: leadership from the top drove extensive heroic collaboration across agencies towards a clear ambitious goal in a compressed period of time. But Year One of UPK also had some non-traditional elements.

First, many people involved felt they were working on a historic, transformative program. Managers, line employees, and data scientists all felt the same way. So did the schools and centers involved in the program. With all of these energetic human arrows pointed in the same direction, the huge scale of the initial launch became-just barely-possible.

Second, data played a starring role in the launch, but that role had a different character in different operational settings. Data science was front and center in the success of the outreach portion of the initiative to which micro-targeting was essential. At the same time, incompatible and over-burdened data systems made the management of the rest of the project-and particularly real-time assessment of enrollment supply and demand as well as the permitting progress of sites-extraordinarily challenging. Heroic problem-solving across agencies by public employees-coupled with a commitment to agility and iteration-was required to overcome those systemic shortcomings.

Third, empowered and talented public employees who understand technology played crucial roles in the UPK rollout. Listen to Lucas Koehler: "It's been so, so incredibly exciting to be part of a major initiative, and to see it go well, and to have data be a big deal. That was very satisfying." Josh Thomases, now at Bank Street, who was at DOE spanning the Bloomberg and de Blasio administrations, says of Sophia Pappas: "She is amazing and is as implementation- 
focused as any human being I've ever met. De Blasio should thank whatever gods he prays to on a regular basis for her existence." Josh Wallack, Alexis Confer, Stacey Gillett, Matthew Klein, Rick Fromberg, Nick O'Brien, and Sohaib Hasan are all data-driven. All of these people were given the running room to solve problems, and they functioned with agility and energy.

The story of universal pre-K is just beginning in the U.S. Like Mayor Bloomberg's Applied Sciences Initiative, which is bringing top-tier applied sciences and engineering campuses to New York City in a bid to dramatically increase the city's potential for economic growth over the next thirty years, we will not know what the payoffs are from the UPK movement for many years. As Josh Wallack says, "You have to keep working for a long time." A child in today's pre-kindergarten class may be in the next generation of students to populate $\mathrm{New}$ York City's applied-sciences campuses-and may someday solve the global warming crisis. And researchers believe children in these pre-K classes will now have the opportunity to thrive.

Some of the preliminary lessons learned from the New York experience might be summed up this way:

- $\quad$ persistent, almost hourly, top-level leadership is essential;

- $\quad$ launching at scale can work;

- $\quad$ getting parents to voluntarily sign up for a new pre-K program and new programs to be ready to open requires a combination of data-driven techniques drawn from modern campaigns and grassroots organizing with an oldfashioned commitment to the role of government;

- data systems and staff ready to wield data need to be in place to make the necessary cross-agency coordination possible; and

- a sense of urgency, agency, and agility on the part of city employees will be helpful. 